MATEC Web of Conferences 3, 01035 (2013)

DOI: $10.1051 /$ matecconf/20130301035

(C) Owned by the authors, published by EDP Sciences, 2013

\title{
Re-investigation of the binary system Phenanthrene/Anthracene
}

\author{
A. Burel, N. Couvrat, S. Tisse, Y. Cartigny, and G. Coquerel \\ Laboratoire SMS, Université de Rouen, Rouen, France
}

\section{Introduction}

Chemical purification of Phenanthrene can be achieved by conventional laboratory techniques, such as preparative HPLC. However, this process presents several drawbacks: i) tendency of adding solvent impurities to the targeted compound; ii) limitations in the separation, especially with other fused ring compounds such as Anthracene, Fluorene, etc. By contrast, the zone melting technique [1] has shown very interesting results in the ultra-purification of several inorganic solids (such as silicon, obtained with $99.999 \%$ of purity) [2], while it is currently not widely used for organic compounds. This process, based on the segregation of impurities by phase separation, involves heterogeneous equilibria and requires a precise description of phase diagrams between the molecule to purify and its impurities.

Zone melting experiments were conducted on Phenanthrene [3, 4] in order to remove its four main impurities: Dibenzothiophene, Carbazole, Fluorene and Anthracene. However, the binary phase diagrams between Phenanthrene and these compounds (described in the literature) were not well and/or fully described, leading us to a systematic re-investigation of these systems.

The current study deals with the re-investigation of the Phenanthrene/Anthracene binary system, which was described in 1957 [5] as fully miscible in the liquid and in the solid state. One can note that this diagram was constructed without structural characterization of phases.

\section{Experimental}

The Phenanthrene and Anthracene used in this study were supplied by Alfa Aesar and given with an indicative purity greater than $98 \%$. It has to be taken into account that both starting products are far from being pure, and thus that the binary compositions can present small range variations.

Binary mixtures of known compositions (in both starting materials) were prepared as following: full dissolution of the physical binary mixtures in acetone, and recrystallization by slow evaporation of the solvent at ambient temperature.

The resulting mixtures were characterized thermally by DSC (heating rate: $5 \mathrm{~K} / \mathrm{min}$ ) and structurally by XRPD analyses.

\section{Results}

By combination of experimental data, this work has highlighted important differences in the phase diagram comparing to that of 1957: a polymorphic transition at $65^{\circ} \mathrm{C}$ of the pure Phenanthrene is established. Consequently, new biphasic domains exist, leading to the presence a peritectic invariant: $\langle$ ss Phen. $\mathrm{HT}\rangle \leftrightarrow \mathrm{Liq}+$ <ss Anthracene> (figure 1).

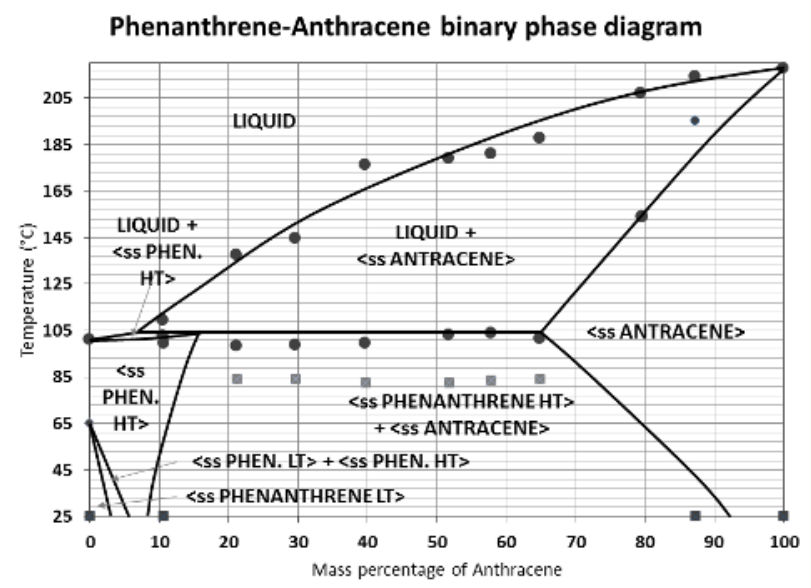

Figure 1. New proposal for Phenanthrene/Anthracene binary phase diagram.

While the nature of most of the domains in the diagram have been determined, some thermal phenomena still need clarification (in particular, a possible invariant transformation at circa $85^{\circ} \mathrm{C}$, gray squares in figure 1). Up to now, no new biphasic domain has been characterized for intermediate compositions (circa 50\% in mass) between $85^{\circ} \mathrm{C}$ and the peritectic temperature $\left(\sim 100^{\circ} \mathrm{C}\right)$, by Temperature-Controlled XRDP.

Even if a new description of the phase diagram can be proposed, there are no direct consequences on the Phenanthrene purification by zone melting. Indeed, the influence of Anthracene on the phase segregation during the refinement of commercial Phenanthrene (containing 
less than $1 \%$ in mass of Anthracene) is consistent with the version of 1957 .

\section{Conclusion}

The combination of thermal and structural analyses led us to propose a new binary phase diagram (at atmospheric pressure) for the Phenanthrene/ Anthracene system. More particularly, a peritectic transformation (previously unknown) and partial solid solutions on both sides of the diagram were evidenced.

Nevertheless, this binary diagram is not fully clarified and further work is required. For example, it is known that Phenanthrene has a clear tendency to sublimation upon heating, which can disturb the extraction of reliable data from DSC measurements.

To conclude, this study has highlighted the importance of re-investigating the a priori non questionable existing data determined several years ago, especially by improving their description with current routine tools.

\section{References}

1. W.G. Pfann, Zone Melting. U.S. patent $n^{\circ} 3423189$ (1969)

2. P.R. Mei, S.P. Moreira, E. Cardoso, A.D.S. Côrtes, F.C. Marques, Sol. Energ. Mat. Sol. Cells (2012)

DOI: http://dx.doi.org/10.1016/j.solmat.2011.1-1.014

3. N. Couvrat, Y. Cartigny, S. Tisse, M.-N. Petit, G. Coquerel, XXXVII JEEP - 37th Conference on Phase Equilibria (2011)

DOI: http://dx.doi.org/10.1051/jeep/201100006

4. N. Couvrat, A. Burel, Y. Cartigny, S. Tisse, G. Coquerel, J. Therm. Anal. Cal. (2012) DOI: $10.1007 / \mathrm{s} 10973-012-2746-\mathrm{z}$

5. M. Brandstatter-Kuhnert, H. Wei $\beta$, Mh. Chem 88 1007 (1957) 